\title{
Potentiometric biosensor for acrylamide determination in wastewater using wild type amidase from Pseudomonas aeruginosa
}

\author{
N. A. F. Silva, D. Gil, A. Karmali \& M. Matos \\ ${ }^{1}$ Chemical Engineering and Biotechnology Research Center, \\ Instituto Superior de Engenharia de Lisboa, Portugal \\ ${ }^{2}$ Instituto Politécnico de Lisboa, Portugal
}

\begin{abstract}
Acrylamide is a toxic amide with potentially hazardous effects on the environment and human health. This paper reports the results regarding the development of a potentiometric biosensor in order to determine the amount of this amide in wastewater samples. The biosystem consisted of whole cells of Pseudomonas aeruginosa containing intracellular amidase activity which hydrolyses acrylamide producing ammonium ion and acrylic acid. The cells were immobilized on the surface of several types of membranes such as polyethersulfone, nitrocellulose and nylon, in the presence of glutaraldehyde as bifunctional reagent, and then attached to the surface of an ammonium ion selective electrode. Polyethersulfone was revealed to be the most adequate in terms of biosensor response. The effect of glutaraldehyde concentration was also studied and $5 \%(\mathrm{v} / \mathrm{v})$ was chosen as the optimum concentration value. The results obtained revealed excellent analytical characteristics of the biosensor such as good linear response in the range of 0.5 to $100 \mathrm{mM}$ of acrylamide, a detection limit of $4.48 \times 10^{-5} \mathrm{M}$, a response time of $55 \mathrm{~s}$, a sensitivity of $58.9 \mathrm{mV} / \mathrm{mM}$. This system was also tested in real samples of complex matrix, namely wastewater from an industrial plant where an average substrate recover of $93.3 \%$ was obtained.
\end{abstract}

Keywords: acrylamide, potentiometric biosensor, wild-type amidase; whole cells, Pseudomonas aeruginosa, wastewater. 


\section{Introduction}

Acrylamide is an amide with potentially hazardous effects on environment and human health. Humans exposed to acrylamide have revealed symptoms such as muscular weakness, skin and mucous irritation, nausea and numbness. In addition acrylamide is a potent neurotoxin that can cause serious nervous system damage. Long term exposure to this chemical may also be responsible for several types of cancer [1-3].

Environmental effects may include death of animals, birds and fish, and death or low growth rate in plants. Accumulation in groundwater may also occur, as well as persistence in aquatic environments $[4,5]$.

Acrylamide is mainly used in the production of water-soluble polymers used as additives for drinking water, in enhanced oil recovery, in wastepaper recycling, as soil conditioning agents, in the synthesis of dyes, in textile industry, as copolymers for contact lenses, in the construction of dam foundations, tunnels, and sewers and in sewage and waste treatment (where high levels of acrylamide can be found) $[6,7]$.

On the other hand acrylamide forms in certain foods, particularly plant-based foods that are rich in carbohydrates and low in protein, during processing or cooking at high temperatures. It has been shown that the presence of reducing sugars and asparagines in foods is responsible for production of significant levels of acrylamide in such foods $[8,9]$.

In this regard it is essential to develop methods in order to determine, reduce and control the amount of acrylamide present in the environment, namely wastewater, as well as in food, human and animal organisms.

Traditionally the determination of acrylamide is performed by LC/MS technique [10], thus time consuming and expensive. Therefore, the development of a biosensor for acrylamide determination in food and environmental samples may result in a significant alternative towards traditional techniques where several advantages like, analyte specificity, easy to operate or low cost equipment can be stressed out.

This work reports the development of a potentiometric biosensor for toxic amides using an ammonium $\left(\mathrm{NH}_{4}{ }^{+}\right)$ion selective electrode (ISE) $[11,12]$. The biocomponent consists of whole cells of Pseudomonas aeruginosa containing intracellular amidase activity. This enzyme catalyses the hydrolysis of aliphatic amides producing the corresponding organic acid (acrylic acid in the case of acrylamide) and ammonium ion which is detected by de selective electrode [13, 14]. The reaction is shown in figure 1.

One of the main advantages in using whole cells of Pseudomonas aeruginosa instead of purified enzymes or cell-free extract containing amidase is the significant decrease in time consuming and financial costs, since some procedures like enzyme purification or cell sonication are overcome.

We believe that this enzyme biosensor can be extremely useful in the detection and determination of acrylamide and formamide in industrial and wastewater samples. This monitorization is essential regarding the reduction of risks for human health and environmental negative consequences. On the other 
hand amidase is of major industrial interest because it can be used in detoxification of industrial effluents containing toxic amides such as acrylamide or formamide [15] as well as in wastewater treatment [16].<smiles>C=C([NH3+])C(=O)O[13CH]=C([18OH])C(=O)O</smiles>

Acrylamide

Acrylic acid

Amonnium ion

Figure 1: Hydrolysis of acrylamide by amidase with formation of acrylic acid and ammonium ion.

\section{Experimental}

\subsection{Reagents and solutions}

Acrylamide solutions, of several concentrations, were prepared from commercial acrylamide, purchased from Merck.

The solvent used in acrylamide solutions was TME $20 \mathrm{mM}$ buffer $\mathrm{pH}=7.2$, containing 20mM Tris-HCl, Riedel deHaen, $1 \mathrm{mM} \beta$-mercaptoethanol, Merck and $1 \mathrm{mM}$ EDTA, Merck.

The various membranes used were Modified polyethersulfone (PES) membranes (Ultrabind, US450 0,45 $\mu \mathrm{m}$ ), purchased from Gelman USA, Porablot ${ }^{\circledR}$ nylon (NY) plus, Porablot ${ }^{\circledR}$ nylon (NY) amp and Porablot ${ }^{\circledR}$ nitrocellulose (NCP), supplied by Macherey-Nagel, Germany.

Glutaraldehyde, used as bifunctional reagent in cells immobilization, was purchased from Sigma.

Membrane cleaning procedure between assays and membrane storage was carried out with TMEGB $50 \mathrm{mM}$ buffer $\mathrm{pH}=7.2$, containing $50 \mathrm{mM}$ Tris- $\mathrm{HCl}$, Riedel deHaen, 1mM $\beta$-mercaptoethanol, Merck, 1mM EDTA, Merck, $10 \%$ (v/v) glycerol, Riedel deHaen and $1 \mathrm{mM}$ benzamidine, Merck.

All solutions mentioned above were prepared with ultra pure (Milli-Q) water with a resistivity greater than $18.2 \mathrm{M} \Omega$, and prepared daily.

A sample of industrial effluent was obtained from an industrial wastewater treatment plant at S. João da Talha, Lisbon.

\subsection{Instrumentation}

The apparatus for potentiometric assays consisted on a Potentiometer ELIT 9801, with an ammonium Ion Selective Electrode, ELIT 8051, a Lithium Acetate Reference Electrode, ELIT 003, a software system, ISE/pH ion Analyzer (v. 6.2.22) and a magnetic stirrer. The acquisition of the resulting data was made by a personal desk computer. 


\subsection{Immobilization of whole cells containing amidase activity}

Frozen cells of P. aeruginosa were suspended in TMEGB 50mM buffer. Membranes were prepared by cutting discs with $20 \mathrm{~mm}$ of diameter. A mixture of $60 \mu \mathrm{L}$ cell suspension with $5 \mu \mathrm{L}$ of glutaraldehyde $(5 \% \mathrm{v} / \mathrm{v})$ was prepared in an eppendorf tube and immediately transferred to the center of the membrane disc. The immobilization of the cells in the membrane's surface [17] was based on covalent bonding due to glutaraldehyde role as a bifunctional reagent. The mixture was then incubated at room temperature for $30 \mathrm{~min}$, and subsequently attached to the surface of the ammonium ion selective electrode using an o-ring. Prior to the first potentiometric assay, the electrode was immersed in TMEGB $50 \mathrm{mM}$ buffer, with magnetic stirring in order to remove unbound whole cells of Pseudomonas aeruginosa from the membrane. This procedure was followed for all parameter optimization and testing assays. The experimental setup is shown in figure 2.

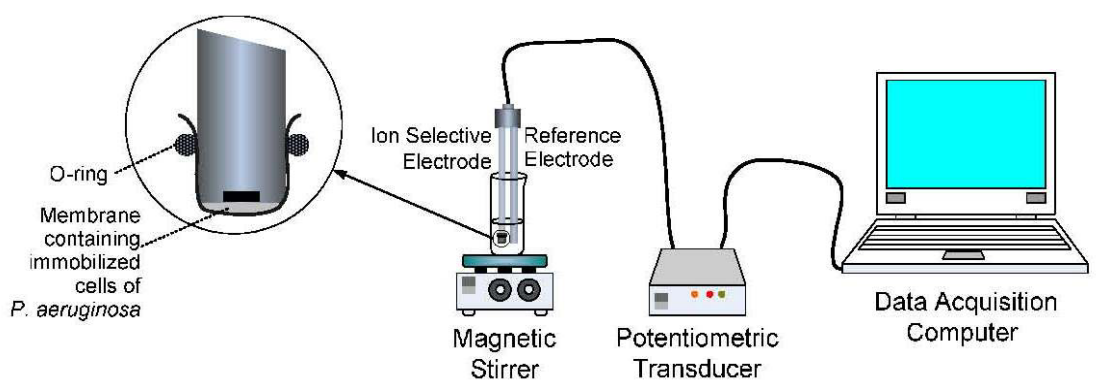

Figure 2: $\quad$ Experimental setup for potentiometric biosensor assays.

\subsection{Potentiometric measurements}

All biosensing potentiometric assays referred to a calibration data firstly constructed and recorded by means of the software system used. In this calibration the potential readings, in $\mathrm{mV}$, are plotted against the logarithm of ammonium ion concentration [18]. The operation of an ion selective electrode is based on the fact that there is a linear relationship between the electrical potential developed between an ISE and a reference electrode immersed in the same solution, and the Logarithm of the activity (or "effective concentration") of the ions in the solution. This relationship is described by the Nernst equation where the slope of the line is an important diagnostic characteristic of the electrode performance. The theoretical value for the slope at $25^{\circ} \mathrm{C}$ is 59.2 for monovalent ions and 29.6 for divalent ions [18].

Biosensor measurements were carried out in a final volume of $5 \mathrm{~mL}$ of acrylamide $0.1 \mathrm{M}$ solution, at room temperature, with magnetic stirring.

As mentioned above amidase catalyses the hydrolysis of amides with formation of the respective organic acid and ammonium ion. This reaction was recorded for a period of 6 minutes where the increase in the amount of ammonium ion produced, given by its concentration, in ppm, or potential values, 
in $\mathrm{mV}$, could be followed. Therefore, ammonium ions formation was measured as a function of time in order to determine the rate, in ppm. $\mathrm{min}^{-1}$ or $\mathrm{mV} \cdot \mathrm{min}^{-1}$, of amidase activity. This parameter was considered as the biosensor's response and thus taken in consideration for all subsequent assays. All measurements were carried out in triplicates. A typical reaction profile can be observed in figure 3 .

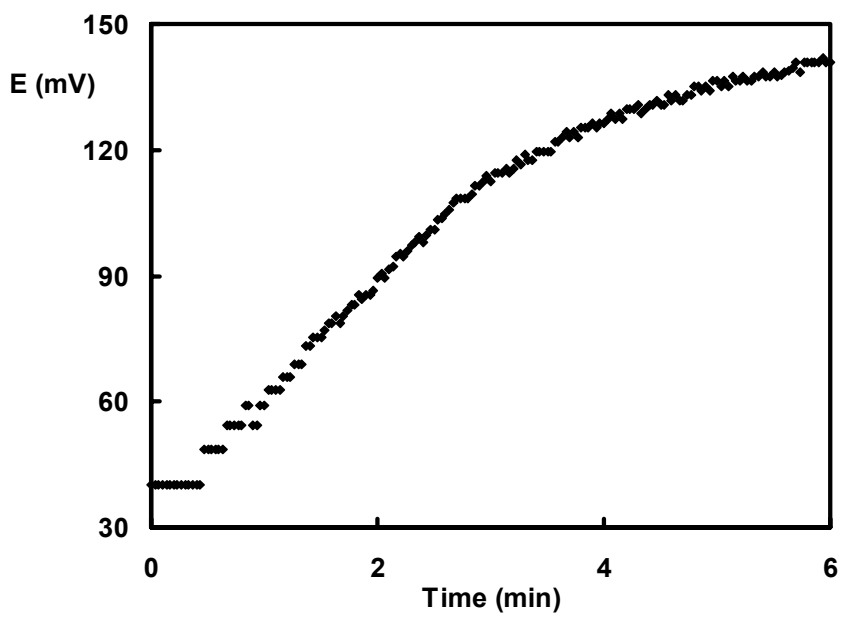

Figure 3: Typical reaction profile showing the increase in ammonium ion concentration resulting from acrylamide hydrolysis by amidase.

The reaction profile clearly proves the significant activity of the whole Pseudomonas aeruginosa cells biosensor towards acrylamide by means of the constant slope after 1 minute of reaction. Also the potential value obtained after approximately half reaction time state that there is not a diffusion resistance imposed by the cell membrane. Therefore, substrate transport and assimilation into the cells are not rate-limiting processes for the whole cell biosensor.

\section{Results and discussion}

Some experimental parameter optimization assays were performed in order to enhance amidase activity and thus the biosensor's response for acrylamide.

\subsection{Effect of glutaraldehyde concentration on biosensor response}

Some experiments were carried out in order to determine the optimum concentration of glutaraldehyde required to obtain the maximum biosensor's activity [19]. These assays were performed by immobilizing, on the surface of a PES membrane, a mixture containing $60 \mu \mathrm{L}$ of whole cell suspension and $5 \mu \mathrm{L}$ of glutaraldehyde solutions in a concentration range of $0-25 \%(\mathrm{v} / \mathrm{v})$. The biosensor response was obtained using as subtract a $0.1 \mathrm{M}$ acrylamide solution in TME buffer $20 \mathrm{mM}$. The results obtained are shown in figure 4 and as it can be seen, 
the biosensor's response increases with glutaraldehyde concentration up to $5 \%$ $(\mathrm{v} / \mathrm{v})$, decreasing from this concentration value onwards. This fact may be due to the increase in the enzymatic film thickness which can pose serious difficulties in the diffusion process in and out of the membrane. Also high concentrations of glutaraldehyde may be toxic to amidase and as a consequence it will result in a significant decrease of its catalytic activity. On the other hand the lowest biosensor response was observed when no glutaraldehyde was used in the immobilization process. In the absence of glutaraldehyde it was observed a leakage of the cells suspension out of the membrane. Facing these results we decided to consider as optimum value, a glutaraldehyde concentration $5 \%(\mathrm{v} / \mathrm{v})$.

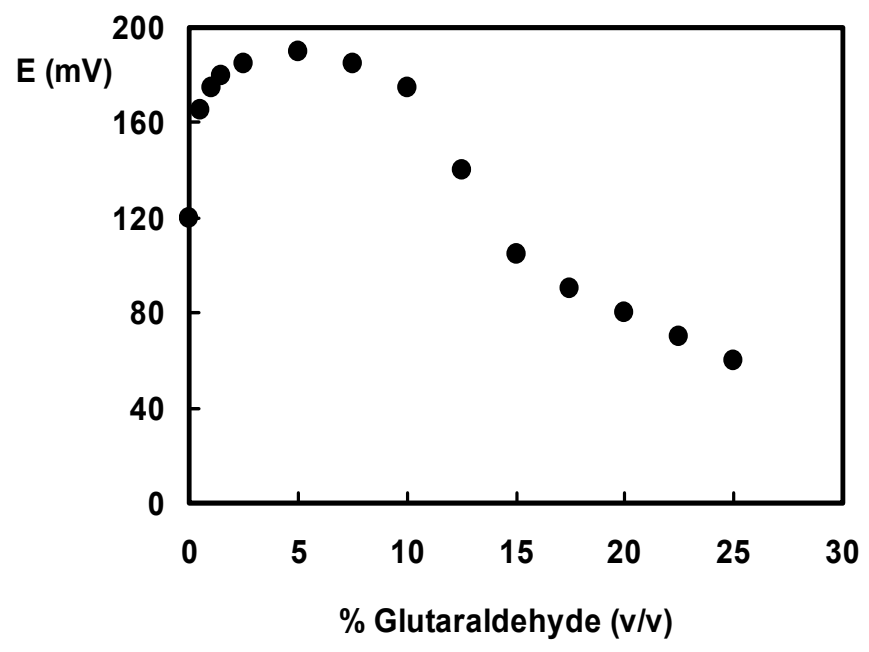

Figure 4: Effect of glutaraldehyde concentration on biosensor's response.

\subsection{Immobilization of whole cells of $P$. aeruginosa on different membranes}

Once the optimum glutaraldehyde concentration was optimized, some assays were performed in order to select the most adequate membrane for immobilization support purposes. Several types of membranes were tested including modified polyethersulfone (PES), Porablot ${ }^{\circledR}$ nylon (NY) plus, Porablot $^{\circledR}$ nylon (NY) amp and Porablot ${ }^{\circledR}$ nitrocellulose (NCP). The biosensor's response was observed for each membrane. The results obtained are shown in figure 5 and allowed us to conclude that in fact PES membranes are far the most adequate for immobilization support purposes, in what the biosensor's response it concerns. This observation may be due to the fact that polyethersulfone membranes contain aldehyde functional groups on both surfaces, thus providing effective covalent binding to amine groups on proteins. Also this membrane's chemistry is inert to moisture and heat which eliminates the need for special storage conditions. Therefore this type of membrane was chosen for all subsequent assays. 


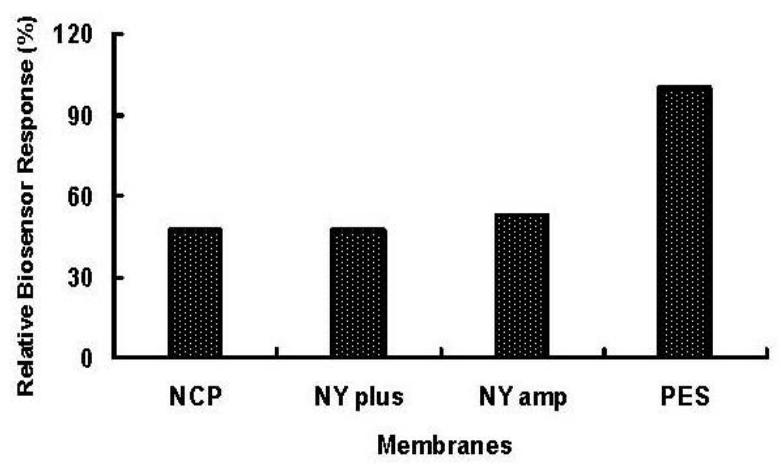

Figure 5: Biosensor's response for several types of membranes.

\subsection{Biosensor's calibration and detection limit for acrylamide}

Following the parameter optimization studies, some analytical characteristics of the biosensor were investigated, namely linear concentration range and detection limit.

The calibration obtained for acrylamide showed a good overall linear relationship between the logarithm of acrylamide concentration and $\mathrm{NH}_{4}^{+}$ formation, given in $\mathrm{mV}$, in the range of 0.5 to $100 \mathrm{mM}$, with a correlation coefficient of 0.999 . The following equation was obtained: $E(\mathrm{mV})=(58.996)$ $\log$ [Acrylamide] + (34.734), where the biosensor's sensibility, given by the equation slope, was found to be $58.996 \mathrm{mV} / \mathrm{mM}$ according to Nernst Equation for monovalent ions.

The calibration plot for acrylamide can be seen in figure 6 , where the significant interval of linearity must be stressed out.

The detection limit of the biosensor revealed to be $4.48 \times 10^{-5} \mathrm{M}$ for acrylamide [20]. On the other hand, the biosensor's response time, defined as the time needed to achieve $90 \%$ of the biosensor response in a given reaction period, was determined to be $55 \mathrm{~s}$.

\subsection{Determination of acrylamide in an industrial effluent matrix}

The application of the present method to the detection and determination of acrylamide in wastewater was investigated by recovery experiments [21] using a sample of real industrial effluent spiked with known amounts of acrylamide. In that way, solutions of $1 \mathrm{mM}, 2 \mathrm{mM}, 4 \mathrm{mM}$ and $8 \mathrm{mM}$ in acrylamide were prepared in effluent matrix and the substrate recovery determined, by measuring the amount of ammonium ion at the end of 6 minutes reaction time. An average substrate recovery in the order of $93.3 \%$ was obtained. The biosensor response is shown in figure 7. 


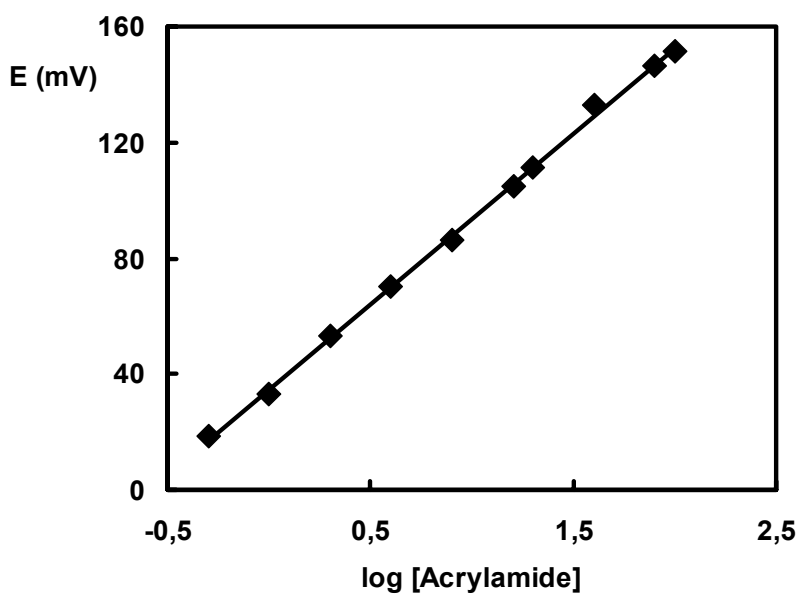

Figure 6: Biosensor's calibration for acrylamide.

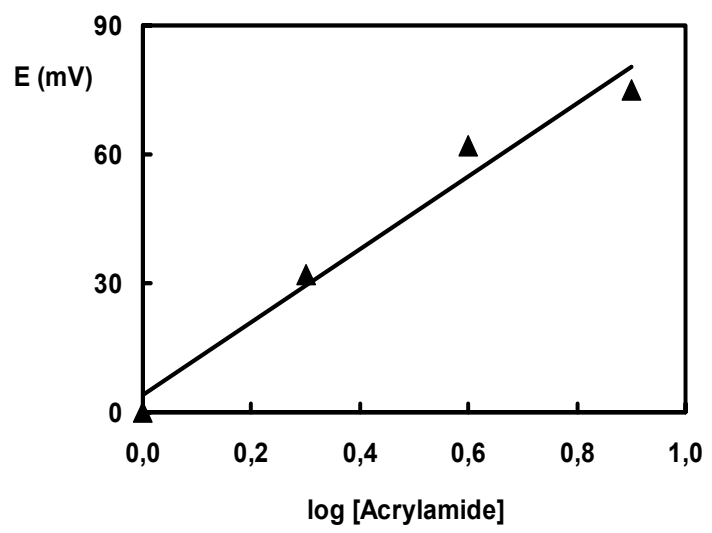

Figure 7: Biosensor response for acrylamide in industrial effluent matrix.

\section{Conclusions and future developments}

The present work involved the design and implementation of a biosensor based on ISE and immobilized whole cells of Pseudomonas aeruginosa containing amidase activity for the detection and determination of acrylamide. This biosensor exhibits a good linear response in the range of 0.5 to $100 \mathrm{mM}$ of acrylamide, a detection limit of $4.48 \times 10^{-5} \mathrm{M}$, a response time of $55 \mathrm{~s}$, a sensitivity of $58.9 \mathrm{mV} / \mathrm{mM}$ and a recovery of $93.3 \%$.

On the other hand, this biosensor presents some advantages towards more classic methods for acrylamide determination, since it involves lower costs, easer 
operation, simplified experimental design and apparatus, and enhanced specificity since it is based on specific enzymatic reaction. The referred characteristics as well as the assays performed with real industrial effluents make us believe that this biosensor may be significantly useful for detection and determination of acrylamide in wastewaters, in the perspective of quality control of the waste produced in several industrial plants. The assessment of drinking and natural waters quality, in what acrylamide presence concerns, may also be a preference field of application for this potentiometric biosensor, since accumulation and persistence in groundwater and in aquatic environments may also occur.

In future work will be developed in order to optimize aspects such as biosensor's half-life time, membrane storage conditions, detection limit, biosensor's design, and the possibility of multi-component and flow analysis of synthetic and real samples containing other toxic amides, such as formamide (already under study), acetamide and others.

The construction of an ISFET based in this system is also one of our main objectives as well as the development of biosensors using "screen printing" technology.

\section{References}

[1] Cheng, N., Wang, J., Complications of breast augmentation with injected hydrophilic polyacrylamide gel. Aesthetic Plastic Surgery, 26, pp. 375-382, 2002.

[2] Gamboa da Costa, G., Churchwell, M.I., Hamilton, L.P., Von Tungeln, L.S., Beland, F.A., Marques, M.M., Doerge, D.R., DNA adduct formation from acrylamide via conversion to glycidamide in adult and neonatal mice. Chemical. Research in Toxicology, 16, pp. 1328-1337, 2003.

[3] Ruden, C., Acrylamide and cancer risk-expert risk assessments and the public debate. Food and Chemical Toxicology, 42, pp. 335-349, 2004.

[4] www.state.nj.us/health/eoh/rtkweb/0947.pdf, Hazardous Substance Fact Sheet, New Jersey Department of health and Senior Services, accessed October 2007.

[5] www.food.gov.uk/multimedia/pdfs/acrylamideback.pdf, Food standards agency study of Acrylamide in Food, background information \& research findings, accessed February 2008.

[6] Othmer, K., Kirk-Othmer Encyclopedia of Chemical Technology, $4^{\text {th }}$ Edition, Eds., J.I. Kroschmitz, M. Howe- GrantJohn, Wiley \& Sons, New York, 1991

[7] Wyatt, J.M., Knowles, C.J., The development of a novel strategy for the microbial treatment of acrylonitrile effluents. Biodegradation, 6, pp. 93107, 1995.

[8] Tareke, E., Rydberg, P., Karlsson, S., Eriksson, S., T“ornqvist, M., Analysis of acrylamide, a carcinogen formed in heated foodstuffs. Journal of Agriculture and Food Chemistry, 50, pp. 4998-5006, 2002. 
[9] Zyzak, D.V., Sanders, R.A., Stojanovic, M., Tallmadge, D.H., Eberhart, B.L., Ewald, D.K., Gruber, D.C., Morsch, T.R., Strothers, M.A., Rizzi, G.P., Villagran, M.D., Acrylamide formation mechanism in heated foods. Journal of Agriculture and Food Chemistry, 51, pp. 4782-4787, 2003.

[10] Rosén, J., Hellenãs, K.E., Analysis of acrylamide in cooked foods by liquid chromatography tandem mass spectrometry. Analyst, 127, pp. 880-882, 2002.

[11] Eggins, B., Biosensors: An Introduction, John Wiley \& Sons, Chichester, 1996.

[12] Mello, L. D., Kubota, L. T., Review of the use of biosensors as analytical tools in the food and drink industries. Food chemistry, 77, pp. 237-256, 2002.

[13] Martins, S., Karmali, A., Serralheiro, M.L., Kinetic properties of wild-type and altered recombinant amidases by the use of ion-selective electrode assay method. Anaytical. Biochemistry, 355, pp. 232-239, 2006.

[14] Andrade, J., Karmali, A., Carrondo, M.A., Frazão, C., Structure of amidase from Pseudomonas aeruginosa showing a trapped acyl transfer reaction intermediate state. Journal of Biological Chemistry, 282, pp. 19598-19605, 2007.

[15] Nawaz, M.S., Khan, A.A., Seng, J.E., Leakey, J.E., Sittonen, P.H., Cerniglia, C.E., Purification and characterization of an amidase from acrylamide-degrading Rhodococcus sp. Applied and Environmental Microbiology, 60, pp. 3343-3348, 1994.

[16] Fournand, D., Bigey, F., Ratomahenina, R., Arnaud, A., Galzy, P., Biocatalyst improvement for the production of short-chain hydroxamic acids. Enzyme and Microbiol Technology, 20, pp. 424-431, 1997.

[17] Chibata, I., Tosa, T., Sato, T., Mory, T., Immobilized Enzymes - Research and Development, John Wiley \& Sons, New York, 1978.

[18] Brett, C. M. A., and Brett, A. M. O., Electrochemistry, principles, methods and applications, Oxford univ. press, Oxford, 1993.

[19] Walt, D., The chemistry of enzyme and protein immobilization with glutaraldehyde. Trends in Analytical Chemistry, 13, pp. 425-430, 1994.

[20] Massart, D. L., Vandeginste, B. G. M., Deming, S. N., Michotte, Y., Kaufman, L., Chemometrics: a textbook, Eds., B. G. M. Vandeginste, L. Kaufman, Elsevier, Amsterdam, 1988.

[21] Andreou, V.G., Clonis, Y.D., A portable fiber-optic pesticide biosensor based on immobilized cholinesterase and sol-gel entrapped bromocresol purple for in-field use. Biosensors and Bioelectronics, 17, pp. 61-69, 2002. 